\title{
Patrimônio Ferroviário: em busca dos seus lugares centrais
}

\author{
Heritage Railway: in search of their central places
}

Maria Emília Lopes Freire, Norma Lacerda

\section{Resumo}

O patrimônio ferroviário é formado por estruturas complexas, em interações socioespaciais - implantadas como uma rede -, vinculadas à história do desenvolvimento científico-tecnológico e à memória social. Assim, elas carregam atributos valorativos portadores de interesse patrimonial. Entretanto, não é possível preservar tudo, é necessário fazer uma seleção criteriosa pautada em argumentos relevantes. Este artigo propõe um arranjo teórico - inspirado na abordagem sistêmica, associada às noções de rede, nodalidade e centralidade -, capaz de fornecer fundamentos analíticos imprescindíveis à identificação, em uma rede ferroviária, das estruturas espaciais e suas relações, caracterizadas como lugares centrais. Tais estruturas, por serem as mais importantes à dinâmica funcional dessa rede, são detentoras de potencial à preservação. É uma proposta, instigada pela iminente perda de estruturas ferroviárias, símbolos representativos de identidades coletivas. A discussão centra-se no primitivo sistema ferroviário implantado no Recife, como parte da Rede Ferroviária Nordeste (Brasil). Esse sistema polarizou funções essenciais, conformando centralidades, em relação aos demais pátios da Rede e nodalidades, ante as inter-relações estabelecidas com as demais redes que recobrem o território. Figuram, portanto, como Lugares Centrais.

Palavras-chave: Patrimônio ferroviário. Rede. Abordagem sistêmica. Preservação. Lugares centrais.

\section{Abstract}

The railway heritage is formed by complex structures and socio-spatial interactions - built as a networklinked to the history of scientific and technological development and to social memory. Thus, these structures carry evaluative attributes, bearers of heritage's interest. However, it is not possible to preserve everything, it is necessary to make a careful selection guided by relevant arguments. This article proposes a theoretical arrangement - inspired by the systemic approach, associated with concepts of network, nodality and centrality - able to provide analytical foundations essential to identify, in a railway network, the spatial structures and

MELF é Arquiteta e Urbanista, Mestre em Desenvolvimento Urbano, e-mail: melopesfreire@hotmail.com

NL é Arquiteta e Urbanista, Doutora em Géographie, Aménagement et Urbanisme, e-mail: norma_lac@yahoo.com.br 
their relations, characterized as central places. Such structures, for being the most important to the functional dynamics of this network, they hold potential to preservation. It is a proposal, instigated by the imminent loss of railway structures, representative symbols of collective identities. The discussion focuses on the primitive railway system deployed in Recife, as part of the Northeast Railway Network in Brazil. This system polarized essential functions, conforming centralities in relation to the remaining network yards, and nodalities, compared to the established interrelationships with other networks that cover the territory. Therefore, they are Central Places.

Keywords: Railway heritage. Network. Systemic approach. Preservation. Central places.

\section{Introdução}

0 interesse pela preservação do patrimônio ferroviário ${ }^{1}$ vem ocorrendo - seja no cenário brasileiro, seja no internacional - associado ao desaparecimento e às perdas iminentes de suas estruturas e elementos, símbolos representativos de identidades coletivas e nacionais. A diferença entre esses dois cenários refere-se à intensidade dessas perdas e à adoção de estratégias para identificação da natureza específica de tais bens. Algumas experiências, feitas na Inglaterra e na Espanha², têm enfatizado a preservação da "arquitetura industrial", ou seja, dos edifícios industriais vinculados aos processos produtivos e aos meios de transporte, comunicação e produção de energia. Embora essa forma de investigação tenha gerado importantes Planos de Salvaguarda para a preservação do patrimônio industrial é preciso ir além, notadamente quanto à maneira de apreender esses bens como estruturados espacialmente em rede. Trata-se de passo, ainda, a ser dado. Ressalte-se que, mais recentemente, assiste-se no Brasil à intensificação do interesse acadêmico, tendo por desdobramento notáveis estudos que vêm sendo desenvolvidas com foco na "arquitetura industrial" (Kühl, 1998; 2008) e na "preservação e restauro urbano em sítios históricos industriais” (Rufinoni, 2013).

\footnotetext{
10 termo "patrimônio ferroviário" é entendido no presente texto à luz do conceito de patrimônio industrial (Carta de Nizhzn Tagil e Princípio de Dublin) no âmbito do patrimônio cultural. Compreende paisagens industriais; elementos e estruturas em relações socioespaciais; tecnologia e técnicas de trabalho; equipamentos de sinalização, manobra e comunicação, infraestruturas e superestruturas da via permanente, maquinarias e ferramentas, e know-how da técnica e do saber ferroviário compreendidos a partir de uma visão sistêmica.

2 Sítio Industrial de Ironbridge Gorge, Inglaterra (http://whc. unesco.org/en/list/371); Plano Nacional do Patrimônio Industrial - Espanha (http://ipce.mcu.es/pdfs/PN_PATRIMONIO_ INDUSTRIAL.pdf).
}

Contudo, cabe ressaltar que, apesar do avanço, em termos de debate sobre a preservação do patrimônio industrial em ambos os cenários, não se pode afirmar que existe uma estratégia de valoração cultural consolidada, que leve a uma efetiva prática de seleção e preservação dos artefatos ferroviários gerados pela industrialização, apreendidos em seu contexto socioespacial.

É fato que o interesse pela salvaguarda do patrimônio ferroviário se vem intensificando e tem atraído à atenção da sociedade. Com efeito, assiste-se, desde meados do século XX, às transformações urbanísticas e paisagísticas, em muitas das áreas centrais das cidades - onde se localizam pátios e conexões remanescentes dos primitivos sistemas ferroviários -, decorrentes de projetos de renovação urbana inadequados, por se apresentam indiferentes às práticas preservacionistas. Ademais, são raros os planos de ordenamento territorial urbano, propondo inserir essas áreas na dinâmica urbana, sobretudo, quanto àquelas de interesse social. São exemplos disso às demolições de edifícios considerados representativos da arquitetura industrial, ocorridas, na década de 1960, em Londres (Bolsa de Carvão e o pórtico da Estação Euston) e, na década de 1970, em Paris (Mercado Central). Tais demolições dão conta da situação que se estende até os dias atuais.

No Brasil, são constantes as notícias relacionadas às demolições e descaracterizações de estruturas ferroviárias. Em Pernambuco (Região Nordeste do Brasil), isso vem ocorrendo desde a primeira metade do século XX. É o caso do complexo ferroviário do Brum, situado na Cidade do Recife, que sofreu mutilações provocadas pelas obras de modernização do Porto. Outro exemplo é o Plano Urbanístico Específico para as áreas do Cais José Estelita, Cais de Santa Rita e Cabanga, elaborado em 2015 pela Prefeitura do Recife, atendendo aos interesses do mercado imobiliário. É 
objeto de contestação judicial, técnica e social. Esta última iniciada pelos movimentos sociais denominados grupo Direitos Urbanos e Movimento Ocupe Estelita. Esse Plano compreende a área onde se insere o pátio ferroviário das Cinco Pontas - primeiro pátio implantado no Nordeste brasileiro e fundador do primitivo sistema ferroviário da Região. A atual organização espacial desse pátio ainda resguarda estruturas e relações socioespacias que oferecem evidências arqueológicas, arquitetônicas e urbanistas referentes às atividades ferroviárias exercidas por esse primitivo sistema; às inovações tecnológicas e à engenharia do passado industrial. São, portanto, testemunhos de uma época que remete à transformação social e cultural, vinculados às atividades e à memória coletiva do trabalho ferroviário e, lamentavelmente, desconsiderados como tais no mencionado Plano.

Face ao exposto, é necessário construir uma estratégia de identificação desses bens, capaz de ir além da apreensão dos edifícios industriais e possa levar à compreensão sistêmica da sua funcionalidade e da sua importância cultural, social e tecnológica. Enquanto isso, as estruturas ferroviárias continuam comumente tratadas como áreas esvaziadas em sua sedimentação histórica, e deixadas em situação altamente vulnerável, expostas a riscos de demolição e disponíveis às explorações do mercado imobiliário e/ou às intervenções urbanísticas, muitas vezes capitaneadas pelo poder público. Sem dúvida, a oportunidade de refletir sobre questões relacionadas à preservação do patrimônio industrial ferroviário permite avançar nas estratégias de valoração cultural de tal acervo. Mais especificamente - assunto que trata este artigo - permite avançar na forma de como identificar os lugares centrais de uma rede, passo primeiro do processo de valoração, uma vez que deve ser acompanhado por outros procedimentos, capazes de captar a importância desses lugares para aqueles que deles participaram.

Diante dessas constatações, pretende-se neste trabalho: (i) evidenciar que a estratégia de valoração cultural do patrimônio ferroviário pressupõe a compreensão sistêmica da natureza dos seus bens e, como desdobramento, (ii) propor um arranjo teórico - inspirado na abordagem sistêmica, associada às noções de rede, nodalidade e centralidade -, capaz de fornecer fundamentos analíticos para identificar os lugares centrais de uma rede ferroviária.

$\mathrm{O}$ argumento será desenvolvido em três etapas. $\mathrm{Na}$ primeira, discorre-se sobre o processo de preservação do patrimônio ferroviário, nos cenários internacional e brasileiro, mostrando as perdas provocadas em decorrência da visão reducionista adotada. Na segunda, apresenta-se a construção do arranjo teórico formatado por meios dos conceitos de rede, nodalidade e centralidade, entrelaçados pelos fundamentos da abordagem sistêmica, com vistas a identificar lugares centrais. Enfim, na terceira etapa, aplica-se esse arranjo teórico na análise das estruturas espaciais e conexões remanescentes do primitivo sistema ferroviário do Recife, identificando seus lugares centrais. Nas considerações finais, lançam-se reflexões sobre a imprescindibilidade da adoção do aludido arranjo, etapa primeira do processo de valoração cultural do patrimônio ferroviário, como dito. A expectativa é subsidiar uma nova práxis preservacionista voltada para o patrimônio ferroviário.

\section{Preservação do patrimônio industrial: contextualização}

0 interesse pela preservação do patrimônio industrial é recente. Podem-se tomar como referência os debates que ocorreram na Inglaterra, na década de 1950, ganhando corpo na década de 1960, e se alastraram por outros países da Europa, como Portugal e França ${ }^{3}$. As discussões foram geradas pela destruição de importantes testemunhos relacionados à indústria, devido aos bombardeios durante a II Guerra Mundial e pelo processo de desindustrialização. Isso motivou intervenções urbanísticas que, muitas vezes, promoveram demolições de estruturas industriais obsoletas e/ou arruinadas, inclusive ferroviárias. Nesses casos, colocava-se em risco a permanência e/ou a compreensão da funcionalidade de alguns sítios industriais (Cordeiro, 2011, p. 155).

Se, por um lado, a devastação patrimonial deixada pela II Guerra Mundial e a desindustrialização provocaram o desmantelamento de parte do patrimônio industrial, por outro, esses acontecimentos contribuíram para despertar o reconhecimento cultural de tais testemunhos industriais, como lugares de memória, representativos de valor identitário dos grupos

\footnotetext{
3 Na França, o motivo que levou às manifestações foi a destruição do Mercado Central de Paris, o Halles Centrales, na década de 1970, em função das intervenções urbanísticas promovidas por Haussmman, com propósitos higienistas e de embelezamento da cidade.
} 
sociais que os vivenciaram. Por isso mesmo, significativos esforços foram realizados no cenário internacional e, mais tarde, no cenário brasileiro, no sentido de promover debates acadêmicos, que viessem subsidiar ações de preservação do patrimônio industrial.

Em âmbito internacional, foram realizadas conferências e instituídos organismos para o trato da questão, como a I Conferência Internacional para a Conservação do Patrimônio Industrial (1973); III Conferência Internacional para a Conservação do Patrimônio Industrial (1978), na qual foi criado o TICCIH - The Internacional Committee for the Conservation of the Industrial Heritage -, organização mundial voltada para a proteção, investigação e documentação do legado industrial. 0 amadurecimento desses debates culminou na elaboração de documentos específicos, a exemplo da Carta de Nizhny Tagil (2003), elaborada pelo The International Committee for the Conservation of the Industrial Heritage (TICCIH), e o Princípio de Dublin (2011), assinado pelo International Council on Monuments and Sites (ICOMOS) e o TICCIH. Cordeiro (2011) ressalta que esses eventos colaboraram não apenas para uma formulação da noção de patrimônio industrial, mas também para a emergência da noção de arqueologia industrial, ambos os termos definidos na Carta de Nizhny Tagil (2003).

Beatriz Kühl (2010) - especialista de referência nos estudos sobre o patrimônio industrial -, referindo-se à Carta de Nizhny Tagil, ressalta que, apesar de definirem o termo patrimônio industrial e oferecerem orientações para detectar os seus possíveis valores, os referidos documentos não mencionam os critérios operativos para reconhecê-los. A Carta anuncia os meios de manutenção e de conservação de tal acervo, fundamentados, inclusive, nas Cartas de Veneza (ICOMOS-UNESCO, 1964) e de Burra (ICOMOS, 1999). Ademais, a mencionada autora enfatiza que a noção de patrimônio industrial oferecida por esse documento se limita à dimensão material do acervo, deixando de fora a sua dimensão intangível, expressa no know-how da técnica, nas memórias e na vida social dos trabalhadores e das comunidades. Essa lacuna de ordem conceitual parece preenchida mediante definição ampliada do termo patrimônio industrial oferecida pelo Princípio de Dublin (ICOMOS, 2011) ao reconhecer a importância de conservar o legado material associado à sua dimensão intangível: "the technical know-how, the organization of work and workers, and the complex social and cultural legacy that shaped the life of communities and brought major organizational changes to entire societies and the world in general".

Nessa perspectiva, destacam-se, no âmbito da prática internacional, (i) o caso pioneiro de preservação do sítio industrial de Ironbridge Gorge 4 (Inglaterra), reconhecido pela UNESCO - United Nations Educational, Scientific and Cultural Organization - como Patrimônio Mundial (1986) e considerado símbolo da Revolução Industrial; e (ii) o exemplo do projeto de intervenção IBA Emscher Park (1990 a 2000), resultado da implantação do Plano de Reabilitação da extensa e antiga zona industrial do RUHR, Alemanha (Cordeiro, 2011). Ambos os casos levaram à conservação dos mais significativos edifícios e infraestruturas (com as maquinarias), que integram os respectivos sítios e conformam a paisagem industrial. Dessa forma, foi mantida a identidade industrial desses espaços e suas respectivas funções, mas, sobretudo, foi preservada a memória coletiva do trabalho e de uma região fortemente marcada pelo processo de industrialização.

No Brasil, as discussões relacionadas às questões da preservação do patrimônio industrial têm por marco a realização do I Seminário Nacional de História e Energia (1986) e a elaboração da Declaração em Defesa das Construções e Instalações Utilitárias (década de 1990) - conhecida como Declaração de Campinas -, elaborada por membros do Grupo de Estudos de História da Técnica, da Universidade Estadual de Campinas (UNICAMP). Considera-se este documento como pioneiro no Brasil, quanto às questões relacionadas à conservação e à tutela de bens vinculados ao processo de industrialização. Em 2003, é formado o Comitê Brasileiro para a Preservação do Patrimônio Industrial, representante do TICCIH no Brasil, mesmo ano da elaboração da Carta de Nizhny Tagil.

Cabe notar que, apesar dos notáveis avanços relacionados ao campo do patrimônio industrial, conforme explanado, percebe-se a carência de estudos aprofundados que possam nortear a difícil questão já levantada por tantos autores ${ }^{5}$ - "como preservar" -, ou seja, como identificar de maneira criteriosa os testemunhos ferroviários vinculados ao processo de

\footnotetext{
4 Nesse complexo foram preservadas: minas de carvão, unidades de processamento, alto-forno, rede ferroviária, infraestrutura e superestrutura, bairro operário e etc. http://whc.unesco.org/ en/list $/ 371 /$ multiple=1\&unique_number $=425$

5 Para citar alguns autores, apresentam-se Kühl (2008), Cordeiro (2011) e Rufinoni (2013).
} 
industrialização como merecedores de serem preservados para a geração presente e futura.

As questões relacionadas ao patrimônio industrial, mais especificamente à preservação do patrimônio ferroviário, vêm sendo enfrentadas pelo órgão federal - o Instituto do Patrimônio Histórico e Artístico Nacional (IPHAN) ${ }^{6}$ - e por órgãos estaduais e municipais de preservação. Das atuações de cada um deles, uma questão merece reflexão: a maneira como o acervo ferroviário edificado vêm sendo apreendido, enquanto bem cultural. A abordagem adotada certamente influencia a identificação dos atributos materiais potencialmente preserváveis e, por consequência, a atribuição dos valores correlatos.

Observa-se, a partir dos processos de tombamento e de valoração cultural ${ }^{7}$, que o entendimento do termo patrimônio ferroviário se restringe aos elementos físicos da produção arquitetônica - em geral, as estações ferroviárias -, fragmentados com relação à lógica funcional da rede na qual estão inseridos, e de forma descontextualizada, no que tange ao território no qual se inscrevem. Não resta dúvida, que as estações são relevantes, como símbolos das memórias individuais e coletivas. Contudo, sozinhas não expressam a importância histórica e cultural do transporte ferroviário, como agente indutor do desenvolvimento científico, tecnológico, social, cultural e urbano de um país.

A percepção reducionista dos bens constituintes de uma rede ferroviária vem deixando de fora do processo de salvaguarda as paisagens industriais, as estruturas e as conexões, além das fontes documentais e dos equipamentos, todos considerados elementos essenciais para compreensão da funcionalidade dessa rede. Apreender o conjunto de tais elementos, notadamente as relações socioespacias e seu funcionamento, é uma condição imprescindível, para conhecer e tutelar os atributos que levam ao seu reconhecimento como bens culturais conformados em rede.

Sendo assim, a prática reducionista tem-se mostrado insuficiente e inadequada frente à complexidade funcional e à natureza específica dos artefatos ferroviários. Como consequência, verifica-se, por um

60 patrimônio ferroviário passa pelo processo de valoração cultural demandado pela Lei 11.483/2007 a qual determina ao IPHAN preservar e difundir a "memória ferroviária".

7 Tombamento (Decreto-Lei no 25/1937) e Preservação da Memória Ferroviária (Lei $\mathrm{n}^{\circ}$. 11.483/2007), respectivamente. Em Pernambuco existe o Tombamento Temático do Patrimônio Ferroviário, edificado, instituído pelo Estado em 2001, por meio da Fundação do Patrimônio Histórico e Artístico de Pernambuco. lado, o desaparecimento de elementos essenciais para a compreensão da funcionalidade da rede e, por outro, o "apagamento" de artefatos testemunhos da memória coletiva do trabalho e da história da configuração espacial das cidades e dos territórios.

Kühl (1998), referindo-se ao patrimônio da industrialização, vem alertando que tais "apagamentos" implicam não somente a perda dos bens materiais, como, sobretudo, o desaparecimento dos modos de produção e da organização do trabalho, legado social e cultural das comunidades.

0 patrimônio histórico que concerne à indústria é especialmente sensível por ocupar, geralmente, vastas áreas em centros urbanos e sua obsolescência e falta de rentabilidade tornam bastante delicada a questão de sua preservação. Desaparecem não apenas os edifícios industriais em si, mas também os vestígios dos produtos ali fabricados, dos métodos de produção, das condições de trabalho e moradia do operariado, das relações sociais e espaciais em uma cidade ou região (p. 221).

Também Cristina Meneguello (2011), referindo-se à dimensão arquitetural dos bens edificados como testemunhos da era da industrialização, chama a atenção para o desmantelamento das estruturas industriais, ressaltando que, diante da sua dimensão territorial, o problema deve ser tratado na escala urbana.

O desmantelamento de edifícios e galpões industriais, oficinas, matadouros, armazéns, linhas férreas e estações de trem, gasômetros, moinhos e fiações, seja pela falta de critérios de valorização por parte dos órgãos oficiais de preservação - que ainda relutam em conceder valores indiscutíveis a esse tipo de bem - seja pela força da especulação imobiliária que centra sua atenção nas rentáveis áreas hoje centrais que esses bens ocupam, fazem do patrimônio industrial um problema urbano em larga escala. A dimensão dos bens ou conjuntos de bens industriais construídos, muitos mal conservados, outros em estado de ruína, e outros tantos sofrendo discutíveis intervenções, nos obrigam a pensar sobre como incluir as preocupações com o patrimônio industrial dentro de políticas de requalificação urbana (p. 1820). 
Claro está que pode ser uma maneira adequada para preservar as especificidades de bens complexos, como os ferroviários. Todavia, tal escolha exige uma investigação dos conjuntos em escala local e regional, como se intenta analisar neste artigo, quando se apreende o primitivo sistema ferroviário do Recife como parte da Rede Ferroviária Nordeste. Segundo Manuela Rufinoni (2013, p. 27), os percursos investigativos de bens culturais devem iniciar com "[...] o conhecimento prévio e requerem [...] um claro entendimento das especificidades que o compõem e que devem ser preservados, sob pena de perdermos os próprios atributos que impulsionaram o seu reconhecimento e a sua valoração".

Nessa direção, os bens constituintes da herança ferroviária hão de ter seu valor cultural investigado por meio de um arranjo teórico capaz de fornecer fundamentos analíticos imprescindíveis à apreensão da natureza específica de tais bens, de forma a preservar sua funcionalidade e sistemicidade.

\section{Arranjo teórico para identificar lugares centrais de uma rede ferroviária regional}

Conforme se anunciou, este artigo pretende evidenciar que a estratégia de valoração cultural do patrimônio ferroviário exige a construção de um arranjo teórico, a fim de identificar, em qualquer rede ferroviária, as estruturas espaciais caracterizáveis como lugares centrais. Também já se ressaltou que esta proposta foi instigada pela iminente perda de algumas estruturas espaciais essenciais à interpretação dos pátios remanescentes do primitivo sistema ferroviários do Recife, integrantes da Rede Ferroviária de Pernambuco que, por sua vez, faz parte da Rede Ferroviária do Nordeste. Sendo assim, antes de apresentar a aludida proposta, importa recuperar brevemente a trajetória histórica da formação da rede pernambucana, para mostrar que sua formação se deu ao modo de rede e, por isso, seu valor patrimonial não deve se restringir a elementos isolados, reduzidos a sua materialidade.

\section{Formação da Rede Ferroviária Nordeste: o primitivo sistema ferroviário do Recife}

O processo de construção das estradas de ferro teve início nos países europeus, primeiramente na
Inglaterra, nos primórdios do século XIX, em meio à crença difusa da busca pelo progresso, então dominando parcela significativa da população, em quase todo o mundo, induzida pelos ideários da Revolução Industrial. As ferrovias despontavam como símbolo dessa Revolução. Revelavam o poder, a velocidade e o avanço da tecnologia que dominava a nova era, com suas obras de engenharia, estações e pontes (Hobsbawn, 1996).

As primeiras ferrovias foram construídas em 1825 , na Inglaterra ${ }^{8}$. Em pouco tempo, espalharam-se pela Europa e Estados Unidos, chegando o surto de implantação no Brasil muito precocemente. Estabeleceram-se no território brasileiro, a partir da segunda metade do século XIX, sob a influência do modelo inglês e seguindo o padrão de concessões para sua construção. Ora seguiam caminhos históricos, construídos no período colonial, acompanhando a costa litorânea do Brasil, ora desbravavam o interior, no sentido perpendicular ou oblíquo ao litoral (PINTO, 1949), com o objetivo de escoar a produção agrário-exportadora - em especial a produção de açúcar, algodão e café -, pelos portos brasileiros.

Em 1957, o Governo Federal encampou as ferrovias existentes, distribuídas em quatro das cinco macrorregiões do Brasil - Nordeste, Centro-Oeste, Sudeste e Sul - e, por meio da Lei no 3.115/1957, criou a Rede Ferroviária Federal S.A. (RFFSA), para administrá-las.

Essas ferrovias foram agrupadas em subsistemas regionais interdependentes, embora conservando suas articulações e inter-relações socioespaciais. A malha férrea brasileira foi concessionada, na década de 1980, mediante o programa de desestatização do Governo Federal.

Pernambuco foi o primeiro estado do Nordeste e o segundo do Brasil a ter uma ferrovia implantada: a Estrada de Ferro do Recife ao São Francisco, cujo primeiro trecho (do Recife ao Cabo) foi inaugurado em 1858. Seguia em direção à região da Mata Sul do Estado, onde se localizava grande parte dos engenhos de cana-de-açúcar. Seu ponto inicial era o pátio ferroviário das Cinco Pontas, situado nas imediações do porto do Recife (Figura 1).

\footnotetext{
8 A estrada de ferro Stockton \& Darlington, com $40 \mathrm{~km}$ de extensão, utilizando locomotiva a vapor, ligava o campo de carvão de Durham ao litoral inglês (Stockton-Darlington).
} 


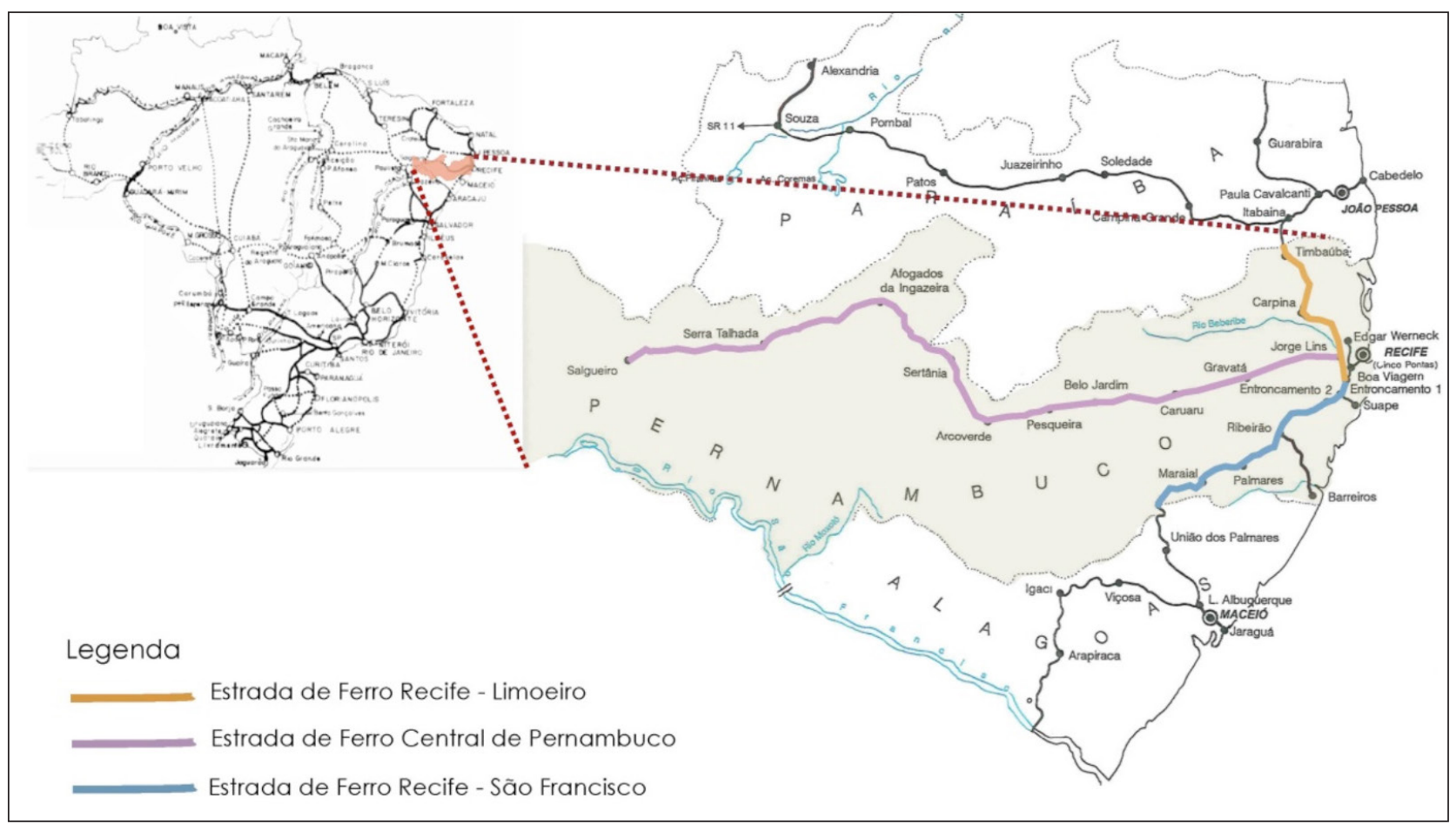

Figura 1 - Rede Ferroviária Federal em Pernambuco.

Fonte: Rede Ferroviária Federal S.A. v.1,1965. Rio de Janeiro. Editado por Clara Torres e Emília Lopes, 2016.

Outras duas importantes estradas de ferro foram implantadas no Estado. Uma foi a Estrada de Ferro do Recife ao Limoeiro, iniciada em 1879: partia do pátio do Brum em direção à região da Mata Norte do Estado, tendo o primeiro trecho (Recife a Paudalho) inaugurado em 1981. Outra foi a Estrada de Ferro Central de Pernambuco: partia do pátio da Estação Central do Recife em direção à região do Agreste pernambucano, com o primeiro trecho (Recife a Tapera) inaugurado em 1885 (Figura 1).

Os demais ramais e desvios industriais foram construídos, conformando a rede ferroviária de Pernambuco e facilitando, assim, o escoamento da produção agroindustrial para o mercado local e, principalmente, para o porto do Recife, seguindo para o mercado externo. Convém registrar que o sistema de bondes implantado no Recife interligava os primitivos pátios ferroviários das Cinco Pontas, da Estação Central e do Brum aos armazéns do Recife Antigo e ao Cais do Porto do Recife. Tais conexões e articulação trouxeram maior fluidez ao território, bem como maior complexidade estrutural e funcionalidade à rede ferroviária pernambucana.

Do exposto, é possível perceber que o patrimônio ferroviário não se restringia a elementos simples e isolados, redutíveis à sua materialidade.
Muito pelo contrário, conformava um objeto complexo, constituído de estruturas, processos e funções que, articulados e interligados pelo entrelaçamento das linhas férreas, constituíam uma rede ferroviária, capaz de viabilizar o deslocamento de mercadorias e passageiros.

\section{Abordagem sistêmica: ponto de partida para desvendar os lugares centrais}

Pelo registro feito, evidencia-se a necessidade de construir um arranjo teórico capaz de revelar a complexidade estrutural e funcional da organização espacial de uma rede ferroviária e destacar os elementos essenciais, relacionados à sua funcionalidade e sistemicidade.

Os fundamentos do pensamento complexo oferecidos pelo filósofo e sociólogo Edgar Morin (1977) mostram-se adequados para dar conta de uma abordagem sistêmica de bens complexos, como os patrimoniais constituintes de uma rede ferroviária. Tal pensamento baseia-se nas teorias da informação, da cibernética e dos sistemas, contrapondo-se à visão reducionista. "É o pensamento capaz de reunir (complexus - aquilo que é tecido conjuntamente), de 
contextualizar, de globalizar, mas, ao mesmo tempo, capaz de reconhecer o singular, o individual, o concreto" (Morin \& Le Moigne, 2000, p. 206).

Kühl (2008) entende, à semelhança do pensamento complexo de Morin, que:

[...] muitos complexos ferroviários são verdadeiras usinas, existindo oficinas de produção de componentes, de montagem e de reparos, que apresentam uma organização do trabalho e encadeamento de produção de fato industrial, caso, por exemplo, das oficinas das antigas companhias ferroviárias Paulista e Mogiana, no Estado de São Paulo (p. 40).

O mesmo acontece com Meneguello (2011) ao ressaltar que:

Estes bens relacionam-se entre si em complexas redes interligadas (como as ferrovias e todos os bens a elas associados) e sua salvaguarda isolada é insuficiente para a compreensão da rede de recebimento de matéria-prima, produção e escoamento que definem a atividade industrial. Pensar nos edifícios industriais, sobretudo, implica em pensar sobre como realizar as escolhas dos exemplares a serem protegidos antes que as reconversões ou, nos piores casos, as demolições, descaracterizem definitivamente sua contribuição para a memória e para a cidade (p. 1820-1821).

Convém insistir que a diversidade e a complexidade funcional e estrutural do patrimônio ferroviário, bem como as paisagens das quais participam, os saberes e os fazeres por ele representado constituem uma dificuldade para a adequada compreensão da sua natureza específica. Importante esclarecer que a complexidade funcional relaciona-se à variedade de funções que podem ser combinadas para cumprir o procedimento operacional do transporte ferroviário. A complexidade estrutural refere-se à variedade do repertório de seus elementos, à forma como o objeto se articula e interage com outros, para desempenhar determinada atividade operativa. Defende-se aqui que a dificuldade ressaltada acima, poderá ser superada por meio de uma análise fundamentada nos preceitos da abordagem sistêmica. Somente assim poder-se-á, de fato, conservar a herança ferroviária, sem mutilar aquilo que constitui a sua própria essência - sua sistemicidade e sua funcionalidade. Essa abordagem, portanto, deve ser o ponto de partida para respaldar a compreensão do patrimônio ferroviário, constituído por estruturas complexas, relacionadas socioespacialmente, conformando uma rede. Tal compreensão constitui subsídio para o processo de reconhecimento do seu valor cultural como testemunhos da história do desenvolvimento científico-tecnológico e da memória social, de tal forma que as propostas de intervenção e de tutela sejam coerentes e conscientes de seus atributos valorativos. Dito de outra forma: o processo de conhecimento e identificação desse legado não pode prescindir de uma abordagem sistêmica, capaz de identificar e desvendar os elementos ferroviários e suas relações, até então ocultos, que podem vir a influenciar a atribuição dos seus valores e seus significados. No entanto, ela sozinha não pode dar conta dessa revelação, devendo, para tanto, associar-se aos conceitos de rede, nodalidade e centralidade, dotados de alto nível de operacionalidade, no sentido de revelar e hierarquizar as estruturas ferroviárias caracterizáveis como lugares centrais de uma rede ferroviária.

0 fato de tratar-se de uma rede reforça a ideia de a visão reducionista mostrar-se inadequada para detectar a complexidade desse patrimônio, na medida em que oculta as conexões e as articulações dos seus diversos elementos ou, em outros termos, considera-os de maneira desarticulada da rede da qual fazem parte e de forma isolada do território no qual se inserem. Consequentemente, decompõe-se aquilo que constitui a própria essência da rede: sua funcionalidade e sua sistematicidade.

Corrêa (2001, p. 107) entende o termo rede, no contexto da geografia, como "um conjunto de localizações geográficas interconectadas (...) por um número certo de ligações", isto é, localizações articuladas entre si por meio de vias e fluxos. 0 autor alude, entre outros exemplos, às agências bancárias com seus fluxos de informação e à rede ferroviária de uma dada região. Por sua vez, Souza (2013, p. 167), complementando o pensamento de Corrêa, descreve uma rede como "um conjunto de pontos (ou nós) conectados entre si por segmentos (ou arcos), correspondentes aos fluxos (de bens, pessoas ou informações), que interligam ou 'costuram' os nós, e podem também indicar elementos infraestruturais presentes no substrato espacial." 0 autor cita, como exemplo, as estradas de ferro, na medida em que viabilizam o deslocamento dos fluxos e conectam cidades, vilarejos e portos. 
0 termo nós nos instiga a tecer considerações sobre o conceito de nodalidade. Segundo Egler (2012, p. 1), não se trata de um conceito novo: foi formulado, em 1902, pelo inglês Mackinder. Para esse autor, significa a "convergência dos sistemas de circulação de mercadorias e pessoas em determinados nódulos." $\mathrm{Na}$ atualidade, a tendência é tomarem-se os termos centralidade e nodalidade como sinônimos. Egler, porém, acompanhando Preston (1971, p. 138), considera que centralidade corresponde à posição do lugar no espaço dos fluxos, enquanto nodalidade é a expressão territorial que fornece a base material, para que a centralidade projete sua área de influência sobre os demais lugares.

Como o patrimônio ferroviário é constituído por bens estruturados em uma rede geograficamente espacializada, o conceito de centralidade - entendido a partir da Teoria das Localidades Centrais (Christaller, 1966) - pode ancorar estudos para identificar e hierarquizar (na organização espacial de uma rede) os lugares centrais, capazes de conservar a compreensão sistêmica da sua funcionalidade. Dito de outra forma, o conceito de centralidade, associado à noção de $l o$ calidades centrais, permite fundamentar um procedimento operativo capaz de identificar quais parcelas dessa rede devem ser preservadas para as gerações presentes e futuras, como testemunho da atividade industrial-ferroviária de um país.

No entendimento de Corrêa (2001), a Teoria das Localidades Centrais de Walter Christaller (1966) é primordial, para fundamentar análises sobre redes urbanas. Essa Teoria considera localidades centrais as cidades que funcionam como distribuidoras de produtos industrializados e serviços às pessoas que residem na sua hinterlândia. Algumas delas exerceram influência sobre outras com as quais se inter-relacionam, assumindo uma hierarquia na rede. Deve-se isso a sua maior capacidade de polarizar ou atrair pessoas e serviços e de controlar a quantidade de fluxos que, realizados por meio dos fixos, perpassam a área considerada.

Cabe pontuar que a nodalidade e a centralidade de um determinado espaço geográfico tendem a coincidir, embora não necessariamente, uma vez que pode ocorrer elevado nível de nodalidade, sem o correspondente fluxo de mercadorias e vice-versa.

De maneira semelhante à colocação de Christaller, as localidades centrais de uma rede ferroviária referem-se àqueles espaços que polarizam funções essenciais, materializadas nas estruturas (estações, almoxarifados, oficinas, vilas, pátios etc.) e conexões (desvios, ramais, linhas-troncos), ou seja, nos fixos que viabilizam os fluxos. Portanto, as localidades centrais que apresentarem maior grau de hierarquia deverão ser as merecedoras de atenção mais urgente por parte dos órgãos preservacionistas e pela sociedade em geral, por constituírem-se testemunhos de uma época vinculada à história do desenvolvimento científico-tecnológico e à memória social.

Como se verá a seguir, as estruturas espaciais e as conexões constituintes do primitivo sistema ferroviário do Recife estiveram relacionadas com a implantação dos sistemas portuário e de bondes, condicionando-a e, ao mesmo tempo, sendo por ela condicionadas. 0 entrelaçamento dessas redes de serviço - ferrovias, bondes e porto - contribuiu para a formação de uma nodalidade, enquanto expressão territorial. Essa nodalidade, impulsionada pela pressão do aumento do deslocamento de pessoas e mercadorias, demandou maior adensamento de fixos e maior intensidade de fluxos, nos pátios ferroviários, objeto desta investigação. Tal situação influenciou diretamente na consolidação da base material das centralidades ferroviárias do primitivo sistema implantado no Recife, permitindo que essas centralidades ferroviárias, detentoras de maiores níveis hierárquicos, projetassem sua área de influência sobre as demais.

\section{Lugares centrais do primitivo sistema ferroviário do recife}

O aporte conceitual e teórico discutido no item anterior foi aplicado na análise do primitivo sistema ferroviário implantado no Recife, a fim de identificar as localidades centrais desse sistema com vistas a subsidiar as ações de tutela do patrimônio ferroviário, a partir da compreensão sistêmica da sua funcionalidade.

Antes de adentrar na aplicação do arranjo teórico proposto, importa registrar que o primitivo sistema ferroviário do Recife é constituído por trechos iniciais das três principais estradas de ferro implantadas em Pernambuco - Estrada de Ferro do Recife ao São Francisco, Estrada de Ferro do Recife ao Limoeiro, Estrada de Ferro Central de Pernambuco -, e pelo Ramal Edgar Werneck (Quadro 1). 
Quadro 1 - Sistema Ferroviário do Recife

\begin{tabular}{c|c|c}
\hline Estrada de Ferro/ Ramal & Trechos ferroviários & Pátios ferroviários \\
\hline Recife ao São Francisco (1858) & Recife a Boa Viagem & Cinco Pontas (Recife), Afogados e Boa Viagem. \\
\hline Recife ao Limoeiro (1881) & Recife a Arraial & Brum (Recife), Encruzilhada e Arraial. \\
\hline Central de Pernambuco (1885) & Recife a Coqueiral & Central (Recife), Ipiranga, Edgard Werneck, Tejpió e Coqueiral. \\
\hline Ramal Edgard Werneck (1939) & Edgard Werneck a Boa Viagem & Edgard Werneck, Ibura e Boa Viagem. \\
\hline
\end{tabular}

Fonte: elaborado pelas autoras (2016) a partir de pinto (1949).

Os aludidos trechos são compostos por leito de linha, incluindo a infraestrutura e superestrutura, e por pátios, estes compostos por terrenos, linhas, edificações, equipamentos e etc., estreitamente imbricados, voltados à circulação de fluxos de passageiros e mercadorias. Os trechos ferroviários descritos no Quadro 1 podem ser visualizados por meio da Figura 2.

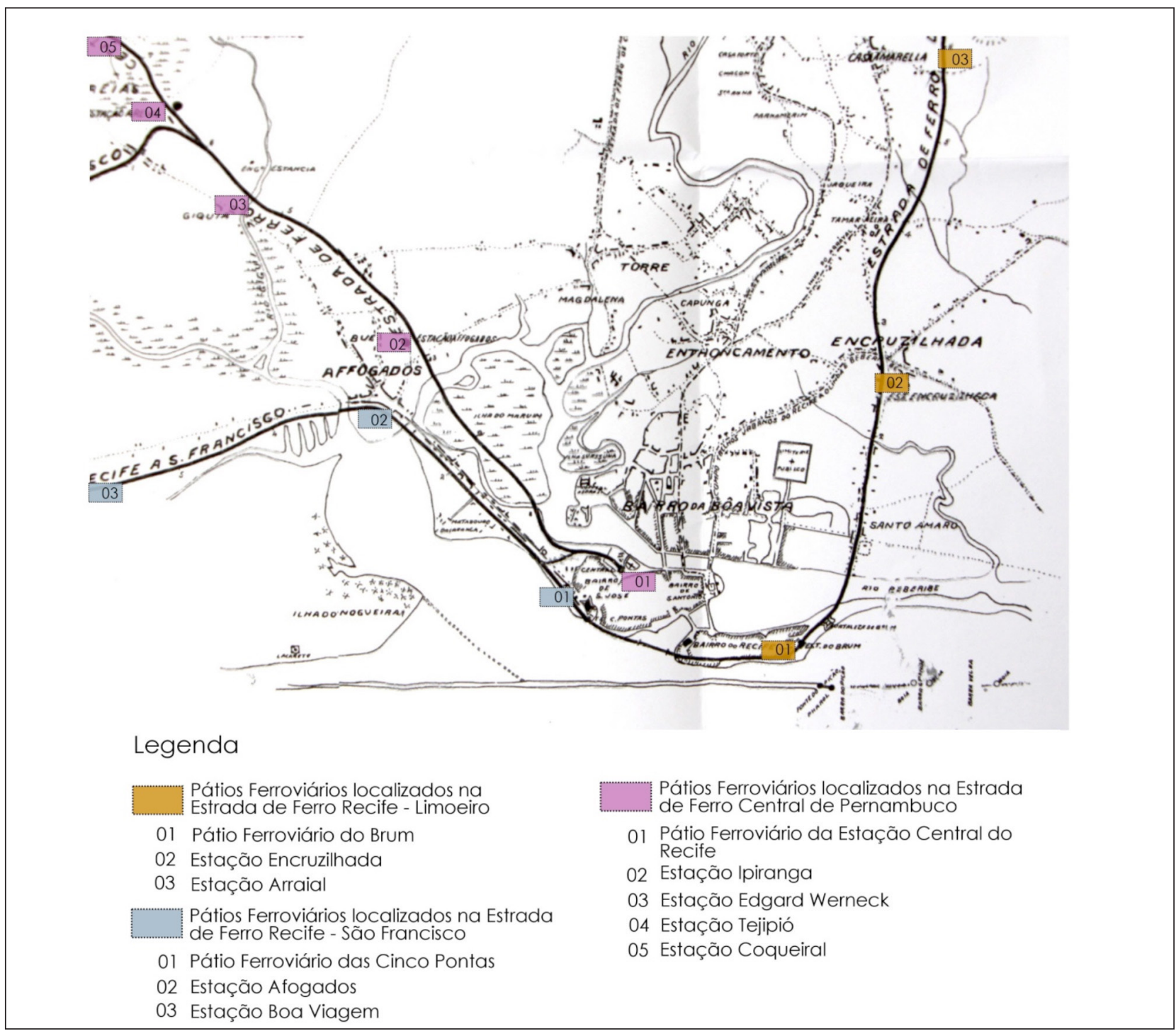

Figura 2 - Primitivo Sistema Ferroviário do Recife.

Fonte: elaborado por Emília Lopes e Clara Torres, 2016, a partir da Planta Geral das Ligações das secções Limoeiro e S. Francisco com a Central de Pernambuco - GWBR, P.L-3, Planta do Acervo da RFFSA, s/d. 
Como se vê, o sistema ferroviário em Pernambuco tem como ponto difusor e irradiador a área central recifense, onde se localiza o Porto, como se pode depreender dos traçados descritos. A expansão das linhas de tal sistema, tanto ao sul como ao norte do Estado, possibilitou sua interligação com outras ferrovias que emergiram dos Estados de Alagoas, Paraíba e Rio Grande do Norte. Formava-se, assim, nos primórdios do século XX, a Rede Ferroviária Nordeste (RFN), uma das primeiras redes regionais a se estabelecer no Brasil. Em 1957, todas as redes regionais brasileiras foram encampadas pelo Governo Federal, criando-se a Rede Ferroviária Federal S. A (RFFSA).

Delimitado o primitivo sistema, retoma-se a aplicabilidade do arranjo teórico enunciado. 0 primeiro passo foi desvendar sua organização espacial. Para tanto, lançou-se mão do conceito de arqueologia industrial ${ }^{9}$ que, associado ao recurso da periodização, permitiu compreender, no tempo histórico, como as estruturas espaciais constituintes desse sistema foram sendo implantadas e conformadas enquanto rede frente às demandas funcionais próprias de cada época.

Como resultado dessa compreensão sistêmica, foram elaborados mapas temáticos e matrizes de relação, a fim de sistematizar os dados. Conhecidas as várias estratificações históricas desse objeto, foi possível revelar elementos até então ocultos que possibilitaram ampliar o conhecimento sobre a funcionalidade do primitivo sistema ferroviário do Recife. Exemplo foi a "descoberta" do Ramal Edgard Werneck como elemento de articulação que permitiu maior fluidez nos fluxos ferroviários, fato que levou as autoras deste artigo a repensar sobre as razões da(s) escolha(s) do que preservar. 0 desvendamento desse elemento e de outros permitiram ainda visualizar o entrelaçamento das demais redes urbanas, notadamente a dos bondes e do porto, que mantinham relação com as ferrovias. Dessa observação pode-se constatar que a conurbação dessas redes se constituiu como uma nodalidade. Em seguida, interpretados esses dados, e voltando-se à análise da organização espacial da rede ferroviária, em Pernambuco, aplicou-se o conceito de centralidade com vistas a identificar, dentre suas estruturas funcionais e relações, aquelas caracterizadas como

\footnotetext{
9 Carta de Nizhny Tagil (TICCHI, 2003).
}

lugares centrais do primitivo sistema ferroviário do Recife. Esses, como dito e justificado, seriam potencialmente merecedores de atenção pelos órgãos competentes e, sobretudo, pela comunidade que os vivenciam, afinal é incontestável o papel simbólico que desempenham como documentos contadores da história da sociedade industrial.

A adoção desse procedimento possibilitou apontar que três pátios ferroviários (Cinco Pontas, Brum e Estação Central) - fundadores das principais estradas de ferro do Nordeste -, o complexo de oficinas (de manutenção e reparo de locomotivas, situado em Edgard Werneck) e a área ferroviária (localizada no Bairro de Boa Viagem), bem como suas conexões socioespaciais - todos situados no Recife e formadores do primitivo sistema ferroviário implantado na cidade - constituíam lugares centrais, em relação às demais estruturas desse sistema e, ao mesmo tempo, nodalidades, em relação às demais redes de circulação (a de bondes e a do porto) com as quais se inter-relacionavam (Figura 3).

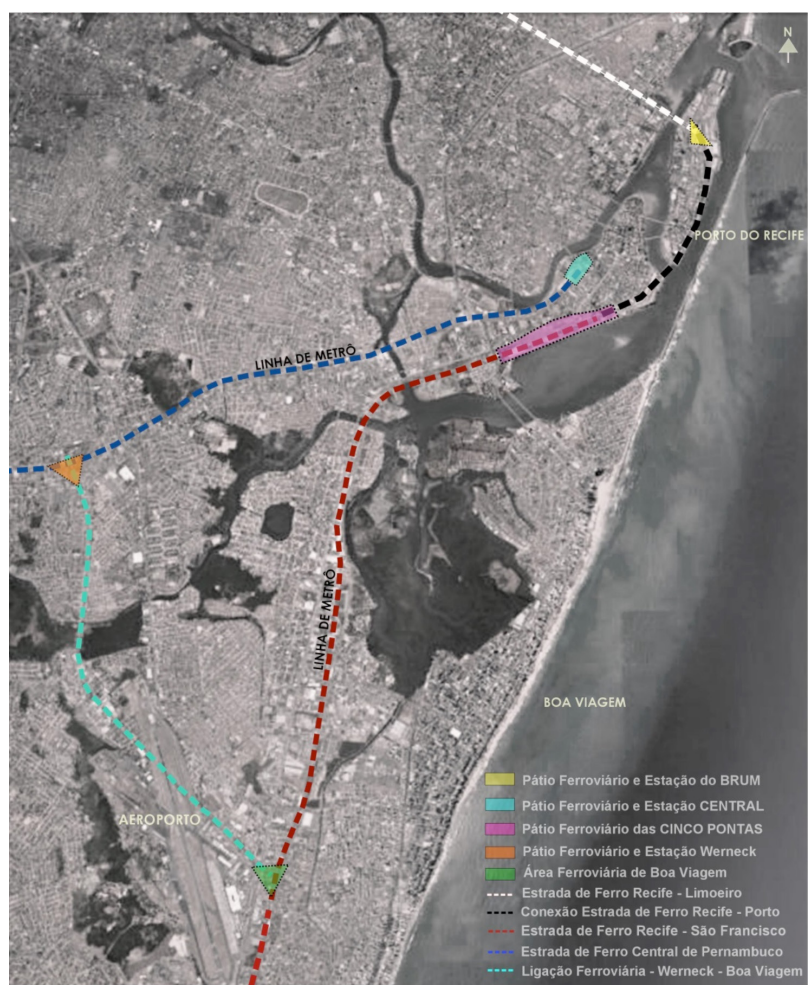

Figura 3 - Lugares centrais e nodalidades do primitivo Sistema Ferroviário do Recife.

Fonte: elaborado por Emília Lopes e Clara Torres a partir da imagem do Google Earth, 2016. 
Os referidos pátios foram identificados como capazes de polarizarem funções e serviços essenciais à operação do sistema ferroviário: reparação e manutenção de material rodante, almoxarifados centrais, soldagem de trilhos, fresadoras, armazenamento de grandes cargas, etc. Importante lembrar que, esses cinco pátios ainda se mantêm conectados e articulados por meio dos fluxos de carga e de passageiros, neste último caso o Metrô de Superfície do Recife.

No que tange aos demais pátios constituintes desse sistema (Quadro 1), a análise revelou que alguns foram desativados e "apagados" da paisagem histórica da Cidade (Encruzilhada e Arraial), enquanto outros foram absorvidos pela logística operacional do Metrô de Superfície do Recife (Afogados, Tejipió, Coqueiral, etc.).

Em síntese, esta análise apontou cinco pátios ou complexos ferroviários e suas conecções remanescentes do primitivo sistema implantado no Recife, considerados lugares centrais dessa rede e lugares nodais do território, os quais, por isso mesmo, carregam artefatos vinculados à atividade ferroviária, em um tempo histórico representativo da memória ferroviária e da memória histórica da cidade.

Para melhor entendimento dos motivos que levaram à identificação desses cinco complexos ferroviários e das suas conexões, faz-se necessário registrar neste artigo, embora de maneira sucinta, a formação histórica de cada um deles.

O complexo ferroviário que deu origem ao primitivo sistema ferroviário do Recife foi o Pátio Ferroviário das Cinco Pontas. Constituiu-se como ponto inicial da Estrada de Ferro Recife-São Francisco, a primeira construída no Nordeste e a segunda no País. Inaugurado em 1858 localizava-se na esplanada do Forte homônimo. Ao longo da segunda metade do século XIX e início do século XX, o pátio foi se expandindo, por meio de acréscimos de terras, em função da demanda açucareira do estado de Pernambuco, assumindo assim papel de destaque na logística do transporte ferroviário de carga e de passageiros. Nas primeiras décadas do século $\mathrm{XX}$, com as obras de modernização do porto do Recife, foi possível, com a construção da Ponte Giratória, estabelecer conexão direta com o porto, reforçando esse espaço como nodalidade e, por extensão, ampliando a base material para que a centralidade projetasse sua área de influência em relação às demais centralidades da rede. 0 aludido pátio conecta-se ao norte com o porto do Recife e o pátio do Brum, e ao sul com o complexo de Boa Viagem.
Até a construção da ponte giratória, as mercadorias e os passageiros trazidos da Mata Sul de Pernambuco eram transportados do Pátio Ferroviário das Cinco Pontas ao porto por meio de bondes e barcos (batelões e alvarengas). A organização espacial desse pátio apresentava uma complexidade ímpar, a exemplo dos grandes armazéns de estocagem do açúcar, oficinas de manutenção do material rodante, posto de abastecimento, vila operária, conjunto de linhas que permitiam formar extensos trens de carga e de passageiros e demais elementos de suporte à sua operação ferroviária.

O Pátio Ferroviário da Estação Central surgiu na década de 1880, servindo de equipamento fundador da Estrada de Ferro Central de Pernambuco, que seguia em direção ao Sertão pernambucano. À semelhança do Pátio das Cinco Pontas, ligava-se ao Porto do Recife por meio do sistema de bondes, que levava passageiros e mercadorias ao Bairro do Recife, robustecendo-o como um lugar nodal. As estruturas e elementos ferroviários e suas conexões foram implantados, visando a atender à crescente demanda econômica do ciclo do algodão e do couro no Estado, o que o caracterizava como um lugar central da rede, por centralizar fluxos e funções essenciais à operação ferroviária, a exemplo dos armazéns, vila operária e demais equipamentos e elementos. 0 aludido complexo foi absorvido pela operação do metrô de superfície da cidade e conecta-se ao pátio de Edgard Werneck.

O Pátio Ferroviário do Brum constituiu-se como ponto inicial da Estrada de Ferro Recife-Limoeiro, sendo seu primeiro trecho inaugurado em 1881. Construída para atender à demanda econômica da Zona da Mata Norte do Estado de Pernambuco, centralizava serviços e funções essenciais para operação dos trens de carga e de passageiros, a exemplo do complexo de oficinas de manutenção do material rodante, dos grandes armazéns, posto de abastecimento e conjunto de linhas que permitiam a formação de extensos trens, a exemplo dos seus pares. Conectava-se diretamente com o porto e com os pátios da Estação Central e das Cinco Pontas, por meio do sistema de bondes ou por linhas do sistema do qual fazia parte. 0 pátio operou até meados do século XX, quando a expansão da atividade portuária foi gradativamente ocupando a área desse complexo e desativando estruturas e funções ferroviárias. Algumas das suas funções foram absorvidas pelo Pátio Ferroviário das Cinco Pontas e pelo Pátio Ferroviário da Estação Central. 
O Pátio Ferroviário de Edgard Werneck, inaugurado na última década do século XIX, constituía um dos pátios formadores da Estrada de Ferro Central de Pernambuco. Ainda resguarda o maior complexo de oficinas de manutenção do material rodante do Nordeste e um dos maiores do Brasil em atividade. Centraliza serviços e funções essenciais à manutenção do material rodante em operação. A área também comporta a estação de passageiros do Metrô de superfície da cidade (nodalidade) e mantém ligação ferroviária com a Estrada de Ferro do Recife ao São Francisco por meio do Ramal Edgard Werneck. É considerado ponto estratégico da logística operacional do sistema.

Por fim, o Complexo Ferroviário de Boa Viagem que, dentro da logística da operação dos trens, exerceu a função de "ponta de linha" do Ramal de Edgard Werneck, o qual exerceu a importante função de interligar a primeira estrada de ferro construída no Nordeste brasileiro - a Estrada de Ferro do Recife ao São Francisco - à Estrada de Ferro Central de Pernambuco. Essa ligação, ainda ativa, promove a estabilidade e a fluidez do sistema. No passado, centralizava o almoxarifado de material de reposição de peças de infraestrutura e superestrutura da via permanente e do material rodante da Rede Ferroviária Nordeste, o que justificava sua função estratégica dentro do sistema.

Atualmente, esses complexos ferroviários, a maioria em atividade, ocupam vastas áreas centrais do Recife, mantendo-se interligado e articulado conformando-se, portanto, um sistema. Com acentuado valor econômico, tais áreas são objeto de considerável pressão do setor imobiliário. Vistas por esse ângulo, elas passam a ser entendidas, por alguns que desconhecem sua historicidade, como um empecilho ao crescimento da cidade, por obstaculizarem a circulação e comprometerem a interligação dos espaços urbanos da Cidade. Por vezes, percebidos inadequadamente como espaços ferroviários esvaziados de suas funções e relegados ao abandono, sua permanência no território se agrava pela ausência de uma política preservacionista, que reconheça sua dimensão cultural como artefatos industriais, testemunhos de uma época que fazem parte da história das cidades e, por isso, deveriam ser integrados à cidade, respondendo, inclusive, aos interesses da coletividade. Caso contrário, tornam-se alvos fáceis de intervenções danosas, que lhes negam valor cultural e dificultam sua reinserção nas dinâmicas da cidade. Em suma, não são reconhecidos como sítios industriais relacionados com a história - do urbanismo, da arquitetura, da engenharia, da técnica e do trabalho - e vinculados às diversas tipologias industriais formadoras do processo de industrialização como um todo.

Por essas razões, acredita-se que esses complexos ferroviários devem ser estudados e tutelados, a partir de um processo de atribuição de valor, ancorado numa abordagem sistêmica articulada aos conceitos de rede, nodalidade e centralidade, considerando os desejos emanados da sociedade. Afinal, trata-se de reconhecer o relevante papel memorial e social que esses complexos ainda exercem, nas estruturas urbanas e na paisagem histórica do Recife.

\section{Considerações Finais}

As reflexões apresentadas no presente texto evidenciam as dificuldades encontradas por especialistas e órgãos de preservação, quando se trata de definir estratégias para identificar o patrimônio ferroviário como um conjunto de bens estruturados em rede, legado caracterizado por sua complexidade estrutural e funcional, diversidade e dimensão territorial. Tais dificuldades devem-se, em grande parte, à ausência de um arranjo teórico que ofereça fundamentos analíticos capazes de apreender, de maneira criteriosa, quais parcelas de uma rede que, em princípio merecem ser consideradas como de interesse para fins de preservação.

Foram exatamente as aludidas características que induziram as autoras deste trabalho a defenderem a ideia da imprescindibilidade de uma análise fundamentada nos preceitos da abordagem sistêmica. Trata-se, indiscutivelmente, de um sistema complexo. Não é sem razão a designação de sistema ou rede ferroviária. Para dar conta, analiticamente, da complexidade desse patrimônio, os conceitos de rede, nodalidade e centralidade mostraram-se operativos, na medida em que foram capazes de nortear o processo de identificação das parcelas desse sistema, a serem preservadas para as presentes e as futuras gerações.

Dito de outra maneira o resultado da aplicação desse desenho conceitual na análise do primitivo sistema ferroviário implantado no Recife evidenciou estruturas espaciais funcionais então ocultas - a exemplo do ramal Edgard Werneck e do Complexo ferroviário de Boa Viagem (lugar de entroncamento ferroviário) - que foram capazes de ampliar o 
conhecimento a respeito do funcionamento anterior desse sistema. Desse modo, a partir de um arranjo teórico criteriosamente construído foi possível identificar os lugares centrais desse primitivo sistema como sendo as parcelas potencialmente merecedoras de serem preservadas. Afinal, essas parcelas articuladas são portadoras de atributos materiais capazes de transmitirem o conhecimento do funcionamento do sistema, ou seja, constituem-se como testemunhos de uma época vinculada à história do desenvolvimento científico-tecnológico, à memória social e à paisagem histórica do Recife.

0 fato de o resultado apresentado parecer bastante relevante no contexto de um processo de valoração cultural, por si só não dá conta em revelar todas as suas características. Trata-se, portanto, de um primeiro passo. Passo que deve ser acompanhado por outros procedimentos - a exemplo da história oral para captar a dimensão intangível desse patrimônio e, assim, certificar-se da sua importância na história do trabalho, na vida social daqueles que participaram desse legado. Adotando esses dois procedimentos sequencialmente complementares -, e outros que sejam pertinentes, é possível captar a real dimensão cultural do patrimônio ferroviário, a própria razão da preservação.

\section{Referências}

Cordeiro, J. M. L. (2011). Problema ou oportunidade? Desindustrialização e Salvaguarda do patrimônio industrial. Oculum Ensaios 13: Revista de arquitetura e urbanismo, do Programa de Pós-Graduação em Urbanismo e à Faculdade de Arquitetura e Urbanismo da PUC Campinas.

Corrêa, R. L. (1987). A periodização da rede urbana da Amazônia. Revista Brasileira de Geografia. Rio de Janeiro, ano 49, 3, 39-68.

Corrêa, R. L. (2001). Repensando a teoria das localidades centrais. Trajetórias geográficas. Rio de Janeiro: Bertrand Brasil.

Christaller, W. (1966). Central places in Southern Germany. Prentice-Hall/ Englewood Cliffs.

Egler, C. A. G. Nodalidade e rede de cidades na América do Sul. Revista Franco-brasileira de Geografia. Recuperado em 20 de fevereiro de 2016, de https://confins.revues. org/7878?lang=pt
Hobsbawm, E. J. (1996). A Era das Revoluções. Rio de Janeiro: Paz e Terra.

Kühl, B. M. (2008). Preservação do Patrimônio Arquitetônico da Industrialização: Problemas Teóricos de Restauro, Ateliê Editorial, Cotia, SP.

Kühl, B. M. (1998). Arquitetura do ferro e arquitetura ferroviária em São Paulo: reflexões sobre a sua preservação, São Paulo, Ateliê Editorial: Fapesp, Secretaria da Cultura.

Kühl, B. M. (2010). Patrimônio industrial: algumas questões em aberto. Arq.urb: Revista eletrônica de Arquitetura e Urbanismo, 3.

Meneguello, C. (2011). Patrimônio industrial como tema de pesquisa. In: Anais do I Seminário Internacional História do Tempo Presente. UDESC, Florianópolis.

Morin, E. (1977). O Método. A Natureza da Natureza. Tradução Maria Gabriela de Bragança - Portugal: Publicações Europa-América, Ltda. $2^{\mathrm{a}}$ edição.

Morin, E. \& Jean-Louís LE M. (2000). A Inteligência da Complexidade. Tradução Nurina Maria Falci - São Paulo: Petrópolis - Série Nova Consciência.

Pinto, E. (1949). História de uma Estrada de Ferro do Nordeste. Rio de Janeiro: José Olympio Editora.

Princípios de Dublin. Documento adotado pela 17aㅡ Assembléia Geral do ICOMOS em 28 de novembro de 2011. Recuperado em 10 de outubro de 2015, de http:// www.international.icomos.org/Paris2011.

Rufinoni, M. (2013). Preservação e restauro urbano: intervenções em sítios históricos industriais. São Paulo: FapUnifesp: Edusp.

Souza, M. L. de. (2013). Os conceitos fundamentais da pesquisa sócio-espacial. Rio de Janeiro: Bertrand Brasil.

The International Committee for The Conservation of The Industrial Heritage (TICCIH). Carta de Nizhny Tagil sobre o Patrimônio Industrial. Nizhny Tagil, 2003. Recuperado em 11 de outubro de 2015, de http://www.mnactec.cat/ ticcih/pdf/NTagilPortuguese.pdf

Submissão: 02/05/2016

Received: 02 ${ }^{\text {nd }}$ May 2016

Aprovação: 25/11/2016

Approved: 25 $5^{\text {th }}$ November 2016 